\author{
Dinesh Rathi \\ School of Library and Information Studies \\ University of Alberta, Edmonton, AB, Canada
}

\title{
Canadian Public Libraries and their Interest in Open Source Software (OSS) (Paper)
}

\begin{abstract}
This study presents findings of research conducted in the Open Source Software (OSS) domain in a Canadian public libraries context. The findings from the survey will provide insight into various facets such as use, benefits and challenges of OSS from Canadian libraries' perspective, OSS evaluation criteria, use of resources to learn about OSS, and decision-making associated with OSS in Canadian libraries context.
\end{abstract}

\section{Introduction}

Information Technology (IT) plays an important role in every sector. It might be argued that technology is critical in libraries as well due to "the plurality of information formats - the electronic [version of content] sitting alongside the printed [version of contents]" (Waan, $1996 \mathrm{p}$. 42), which require software applications to allow users to access material available as eresources. Organizations such as libraries can use proprietary and/or Open Source Software (OSS)-based technologies to meet their operational needs (e.g., digital library application) and to provide access to resources in digital formats as well as to meet their employees (e.g., productivity software) and patrons' needs.

Prior to the rise in popularity of OSS products, organizations had limited options in the form of proprietary software (PS) products to use them to meet their technological requirements. The rise in popularity of OSS is due to a number of reasons such as low up-front costs, quick updates and bug fixes, vendor neutrality, and licensing terms (Bretthauer, 2001; Crowston and Howison, 2005; Raymond, 1999; Boulanger, 2005) and thus, OSS products are a becoming a strong competitor to PS products in many domains including the Library and Information Science (LIS) domain (e.g., Integrated Library Software (ILS)). OSS products used in libraries have been studied by a number of researchers (e.g., Breeding, 2008, 2009, 2017; Pyati, 2009; Payne and Singh, 2010; Singh, 2013a, 2013b; and Pruett and Choi, 2013) but there are a limited number of studies in this domain focusing on the Canadian context (e.g., Paré et al., 2009).

The focus of this study was on the Open Source Software (OSS) domain in Canadian libraries to gain insight into various facets including use, benefits and challenges of OSS from Canadian libraries' perspective, resources used to learn about OSS products and evaluation criteria used in OSS selection by Canadian libraries, etc. 


\section{Literature Review}

There are many examples of software created in OSS domains which are used by organizations, including libraries, around the world. Some of the inspirational OSS products developed and implemented include:

- Koha and Evergreen in the Integrated Library System (ILS) domain (Breeding, 2008; Breeding, 2017)

- Moodle and OpenUSS (learning management systems) in the educational domain (Dinevski, 2008)

- Greenstone, Omeka, DSpace and Eprint in the digital library domain (Crowe et al., 2010; Andro et al., 2012).

Scholars have explored OSS domains from multiple perspectives, including programmers' motivations in contributing code, the structures of OSS communities, and the support and services models created by organizations, including peer-to-peer help to resolve issues related to OSS products (Bonaccorsi and Rossi, 2003; Paré et al., 2009; Dahlander and Magnusson, 2005; Crowston and Howison, 2005; Lakhani and von Hippel, 2003; Waring and Maddocks, 2005; Singh et al., 2006). In the context of OSS for library work, researchers have examined various facets such as OSS ILS migration (e.g., Singh, 2017; Helling, 2010), challenges and benefits of OSS (e.g., Rafiq, 2009; Karels, 2003; Pyati, 2009; Paré et al., 2009; Singh, 2014) and user experience (e.g., Chen, and Albee, 2012). Majority of such studies are from non-Canadian context and there is a lack of examples from Canadian public libraries in the OSS domain. For example, Pruett and Choi (2013) discussed a number of case examples based on other authors' work such as Genoese and Keith (2011), Helling (2010) and Walls (2011) (as cited by Pruett and Choi, 2013) in OSS-library domain and none of the examples noted in the paper were from a Canadian context.

\section{Methodology}

A survey was conducted with libraries of different types and varying sizes (e.g., small, medium) operating in different geographical locations (e.g., urban, rural) across Canada. The survey was hosted using Survey Monkey (https://www.surveymonkey.com) and distributed to libraries by email. The questions included in the survey focused on various topics such as kind of OSS products used in organization, decision making and support for OSS products, benefits and challenges related to OSS products, and others. Literature from the OSS domain was the inspiration for identifying themes for survey questions, and modelling survey questions for this research (e.g., Lakhani and von Hippel, 2003; Surman and Diceman, 2004; Singh et al., 2006; Paré et al., 2009; Singh, 2013a).

An email list associated with academic and public libraries operating in Canada was created by consulting online and publicly accessible resources such as the Canadian Association of Research Libraries, the LibWeb directory of Libraries in Canada, and provincial/territorial listings of public libraries and academic institutions. The survey was emailed to over 2,100 recipients in various libraries across Canada. The survey might have been received by more than one recipient in the same library system. Over 120 recipients opted to participate in the survey and 84 participants completed and submitted their responses. This was assessed by response to the last question in the survey (i.e., "I agree to submit my responses"). Please note that questions 
in the survey were not mandatory, thus respondents who completed and agreed to submit the survey may have skipped some questions in the survey.

\section{Key Findings}

The majority of the respondents identified their library location as rural (i.e., 69\%) as noted in the demographics section of the survey. There were a number of interesting findings from the study. The following bullet points provide an overview of key findings from the survey relevant to the context of public libraries:

- Limited number of public libraries used any OSS product(s) i.e., just over $40 \%$ respondents noted that their libraries used any OSS product(s) and over 35\% of respondents noted that their library did not use any OSS product.

- Though limited number of participating libraries used OSS products but they used wide ranging OSS products. Examples of some of the key OSS-based products used include Integrated Library System (ILS) (e.g., Evergreen), Content Management System (e.g., Joomla, Drupal), and Database management systems. The users also used 'other' OSS-based products such as citation management software and office productivity software (e.g., Libre Office).

- A majority of the respondents (over 70\%) noted that their library had no policies and/or procedures regarding the research, acquisition, and implementation of OSS products.

- A large number of respondents ( 69\%) suggested that employees at senior positions such as the library director/head librarian are the decision makers regarding the use of (or not) OSS product and/or migration to OSS products in their library.

- Respondents identified a number of resources that libraries used to find information about OSS products and these include colleagues/other local library staff, other libraries/non-local library staff, product websites, electronic databases and other resources such as Github, social media tools like Twitter, library periodicals, and library consortia website(s).

- Libraries used various criteria to a varying degree to evaluate OSS products. These include cost, ease of use/usability, reliability, flexibility/customizability, help/support options, language options, interoperability, and scalability.

- The respondents also highlighted a number of benefits and challenges in the use of OSS products, reaffirming as noted in the literature (e.g., Rafiq, 2009; Karels, 2003; Pyati, 2009; Paré et al., 2009; Singh, 2014). Some of the benefits noted were: "low cost", "no vendor lock-in" or "no licensing gouges from vendors", more affordable than proprietary software, and a surprising benefit as noted by one of the respondents, "connections to other participating libraries which fosters a collaborative public library community and a sharing of resources". Some of challenges included were: technical (or maintenance) support, lack of familiarity among patrons leading to more training and troubleshooting, and time consuming to update.

- The survey also identified factors that have prevented (or are preventing) libraries from the use of OSS products and these include "libraries are used to maintenance contracts", "user familiarity", comfort of using current products, and lack of IT support and product information. 
The presentation at the conference will share additional findings in areas such as factors influencing a library's decision to migrate to OSS products, and resources used in training staff in libraries. The findings from this study will help researchers and library staff to learn more about the opportunities, benefits, and challenges of using OSS products and also gain more insight into OSS domain in Canadian public library context, and add to the growing body of OSS-related literature in library domain as well.

\section{Conclusion, Limitations, and Future Work}

This study focused on OSS and public libraries in the Canadian Context. The majority of respondents to this survey were from libraries located in rural area. The findings suggest that OSS-products are not as widely used as anticipated i.e., only two-fifth of the respondents noted the use of OSS-based products in their libraries, but it was interesting to find that a number of OSS products are currently being used in Canadian public libraries. Some of the benefits and challenges noted by respondents reaffirm findings from the earlier studies.

One of the key limitations of the study is the limited participation in the survey even though the survey was sent to a large number of public libraries. Future work will focus on conducting semi-structured interviews with librarians to gain an in-depth understanding on various issues such as management perception and support for OSS initiatives, total cost of ownership in running OSS software, and lesson learned from long term use of OSS. In addition, future work will also investigate gaps in LIS education in context of OSS domain, and if such gaps are impacting the adoption and use of OSS in libraries.

\section{Acknowledgments}

This research was funded by the Coutts-Clarke Fellowship, Faculty of Education, University of Alberta, Edmonton, Canada.

\section{References}

- Andro, M., Asselin, E., and Maisonneuve, M. (2012). Digital libraries: Comparison of 10 software. Library Collections, Acquisitions, and Technical Services, 36(3-4), 79-83.

- Bonaccorsi, A., and Rossi, C. (2003) Why Open Source software can succeed, Research Policy, 32 1243-1258.

- Boulanger, A. (2005) Open-Source Versus Proprietary Software: Is One More Reliable and Secure than the Other?, IBM Systems Journal, 44(2), 239 - 248.

- Breeding, M. (2008) Major Open Source ILS Products, Library Tech. Reports, 44(8), 16-31

- Breeding, M. (2009). The viability of open source ILS. Bulletin of the Association for Information Science and Technology, 35(2), 20-25.

- Breeding, M. (2017). Chapter 3. Evergreen. Open Source Library Systems: The Current State of the Art, Library Technology Reports, 53(6), 18-24.

- Bretthauer, D. (2001) Open Source Software: A History, UConn Libraries Published Works, Paper 7. As accessed on November 12, 2013 from http://digitalcommons.uconn.edu/libr_pubs/7. 
- Chen, H. L., and Albee, B. (2012). An open source library system and public library users: Finding and using library collections. Library \& Information Science Research, 34(3), 220227.

- Crowe, J., Hodge, G., and Redmond, D. (2010). Grey Literature Repositories: Tools for NGOs Involved in Public Health Activities in Developing Countries. In Farace, D. J. and Schöpfel, J. (eds.), Grey Literature in Library and Information Studies,.199-214, Berlin/New York: Walter de Gruyter GmbH.

- Crowston, K. and Howison, J. (2005) The Social Structure of Free and Open Source Software Development, First Monday, 10(2). As accessed from http://firstmonday.org/htbin/cgiwrap/bin/ojs/index.php/fm/article/viewArticle/1207/1127.

- Dahlander, L. and Magnusson, M. G. (2005) Relationships between open source software companies and communities: Observations from Nordic firms, Research Policy, 34(4), 48193.

- Dinevski, D. (2008) Open Educational Resources and Lifelong Learning, Proceedings of the ITI 2008 30th International Conference on Information Technology Interfaces, 117-122, Croatia.

- Genoese, L., and Keith, L. (2011). Jumping ship: One health science library's voyage from a proprietary ILS to open source. Journal of Electronic Resources in Medical Libraries, 8(2), 126-133.

- Helling, J. (2010) Cutting the proprietary cord: A case study of one library's decision to migrate to an open source ILS, Library Review, 59(9), 702-707.

- Karels, M. J. (2003). Commercializing open source software. Queue, 1(5), 40.

- Lakhani, K.R. and von Hippel, E. (2003) How Open Source Software Works: "Free" Userto-User Assistance, Research Policy, 32(6), 923-943.

- Morgan, S. (1996) Developing Academic Library Skills for the Future, Library Review, 45(5), $41-53$.

- Paré, G., Wybo, M. D. and Delannoy, C. (2009) Barriers to Open Source Software Adoption in Quebec 's Health Care Organizations, J. Med System (Journal of Medical System), 33, 1-7.

- Payne, A. and Singh, V. (2010) Open Source Software Use in Libraries, Library Review, 59(9), $708-717$.

- Pruett, J., and Choi, N. (2013). A comparison between select open source and proprietary integrated library systems. Library Hi Tech, 31(3), 435-454.

- Pyati, A. (2009) Open source Software and Libraries, Information Technology in Librarianship, 207-20.

- Rafiq, M. (2009). LIS community's perceptions towards open source software adoption in libraries. The International Information \& Library Review, 41(3), 137-145.

- Raymond, E. (1999) The Cathedral and the Bazaar, Knowledge, Technology, and Policy, 12(3), 23-49.

- Singh, V. (2013a) Why Migrate to an Open Source ILS? Librarians with Adoption Experience Share their Reasons and Experiences. Libri, 63(3), 206-219.

- Singh, V. (2013b) The Nuts and Bolts of Migration to Open Source ILS: Experiences and Recommendations from Librarians. Libri, 63(2), 108-122. 
- Singh, V. (2014). Expectations versus experiences: Librarians using open source integrated library systems. The Electronic Library, 32(5), 688-709.

- Singh, V. (2017). Open source integrated library systems migration: Librarians share the lessons learnt. Journal of Librarianship and Information Science, 0961000617709059, 1-10. Available at: https://doi.org/10.1177/0961000617709059.

- Singh, V., Twidale, M.B., and Rathi, D. (2006) Open Source Technical Support: A Look at Peer Help-Giving, Proceedings of the 39th Annual Hawaii International Conference on System Sciences (HICSS '06), 118c.

- Surman, M., and Diceman, J. (2004) Choosing Open Source: A Guide for Civil Society Organizations. Available at https://marksurman.commons.ca/publications/choosing-opensource-a-decision-making-guide-for-civil-society-organizations/full-text/.

- Ven, K., Verelst, J., \& Mannaert, H. (2008). Should you adopt open source software?. IEEE Software, 25(3), 54-59.

- Walls, I. (2011). Migrating from Innovative Interfaces' Millennium to Koha: The NYU Health Sciences Libraries' experiences. OCLC Systems \& Services: International digital library perspectives, 27(1), 51-56.

- Waring, T. and Maddocks, P. (2005) Open Source Software Implementation in the UK Public Sector: Evidence from the Field and Implications for the Future, International Journal of Information Management, 25(5), 411-428. 